\title{
New Leiderman-Khlystov Coefficients for Estimating Engine Full Load Characteristics and Performance
}

\author{
Dariusz Szpica* (1)
}

\begin{abstract}
The paper presents a method of calculating the full load engine characteristics based on the Leiderman-Khlystov relation. Because the values of the coefficients of the discussed function available in literature were determined for obsolete engine designs, an attempt was made to update them. To this end, a chassis dynamometer was used where a database of results had been built for a variety of vehicles. Following the data collection, the coefficients for variety of fueling system (six groups: fuel injected gasoline and turbocharged gasoline, spark ignition LPG I-II and IV generation, naturally aspirated diesel and turbocharged diesel) were determined. The identification of the coefficients was carried out in Matlab-Simulink indicating the applicability of the said function for most of the engines, yet the recent popularity of turbocharged gasoline engines requires an additional analysis of the possibility of use of a different functional description. The full load engine characteristics is a basis for the vehicle performance characteristics and, further, for modeling of traffic in a variety of aspects of the vehicle operation.
\end{abstract}

Keywords: Passenger car, Combustion engines, Full load engine characteristics, Numerical identification

\section{Introduction}

Despite the fact that hybrid vehicles are offered increasingly, the prevailing source of propulsion are still gasoline and diesel internal combustion engines. An appropriate combination of the elements of the drivetrain must always be made with respect to the vehicle performance. The selection of the engine is usually a combination of technical, economical and ecological aspects. A task of a designer is to make the right choice while facing contradictory factors. The selection of power output on the wheels must allow for the most important criteria for a given vehicle type. For a passenger vehicle, it is the maximum speed and acceleration.

During the design of the drivetrain it is necessary to determine the engine power output and torque as a function of engine speed (full load characteristics) assuming: maximum power output, engine speed and type of fueling system as the input data.

*Correspondence: d.szpica@pb.edu.pl

Department of Mechanical Engineering, Bialystok University

of Technology, 15-351 Bialystok, Poland
The full load engine characteristics obtained in this way (Figure 1) allows determining of the performance characteristics of the vehicle (Figure 2) and a continuation of further calculations.

The calculations may be related to the vehicle maintenance/operation and vehicle performance. The differences in the values of the engine indexes at $(100,75$, $50,30) \%$ of the power have been presented because the engine does not always operate at full load [1]. The full load engine characteristics and, thus the performance characteristics constitute bases for the calculations related to the traffic flow on the roads or the automation of the traffic lights operation.

The full load engine characteristics can be used in many aspects, such as modeling of the vehicle in motion-performance with automatic transmission [2, 3], vehicle body behavior $[4,5]$, performance under different soil conditions [6], when changing lanes [7] or the assessment of motion stability-vehicle-driver in the ADA method [8]. 


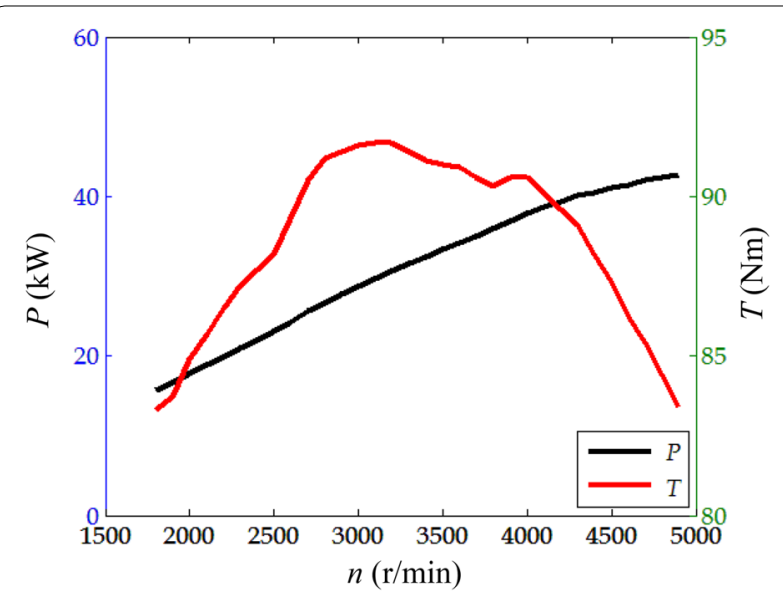

Figure 1 External characteristics of engine

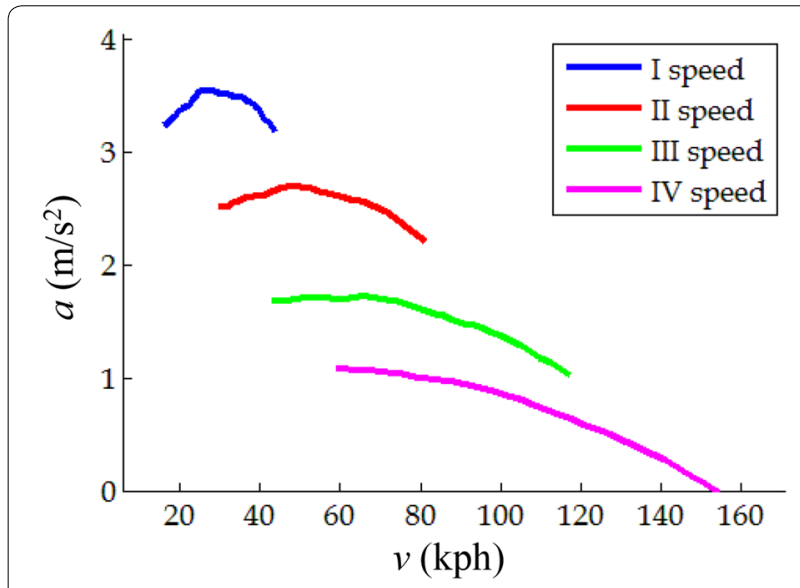

Figure 2 Tractive characteristics for a manual transmission

Additionally, the introduction of the said full load engine characteristics as additional information allows a virtual diagnostic assessment in real time (as has been proposed by An et al. [9] or a vehicle acceleration simulation by Stonys et al. [10]).

Full load engine characteristics is also needed for safety issues such as the influence of the driver and vehicle characteristics on the speed-related decisions of the driver on the roads as well as road safety by Rothengatter and Debruin [11].

The simplest method of calculating the full load engine characteristics is the application of the Leiderman-Khlystov relation whose coefficients are obsolete for modern vehicles. On the other hand, based on commercial software (GT Suite) we can calculate the characteristics but the workload will be much higher [12]. In this case, the investigations are based on a particular engine type and in the previous case, generalizations are allowed.

\section{Engine Characteristics}

The connection between power $P$ and torque $T$ is determined by relation:

$$
T=\frac{P}{2 \cdot \pi \cdot n}[\mathrm{~N} \cdot \mathrm{m}] .
$$

For the comparison of engines, which facilitates their applicability for performance purposes, a coefficient of engine flexibility $E=e_{T} e_{n}$ is applied, being the product of the coefficient of torque:

$$
e_{T}=\frac{T_{\max }}{T_{P \max }},
$$

and the coefficient of flexibility of the engine speed:

$$
e_{n}=\frac{n_{P \max }}{n_{T \max }} .
$$

The values of flexibility of different groups of engines are given by Grishkevich [13], Myslowski and Koltun [14] wheras those of the 1.9 TDi engine by V.A.G by Szpica and Czaban [15], and also Szpica [16].

In practice there is a need of an approximated determination of the full load engine characteristics in case there are no detailed manufacturer specifications and we know only two points of the characteristic: $T_{\max }$ at $n_{T \max }$ and $P_{\max }$ at $n_{P \max }$. Then assuming:

$$
\lambda=\frac{n}{n_{P \max }} .
$$

Usually for carburetor engines without the engine speed limit $\lambda_{\max }=1.15, \ldots, 1.30$; for other engines with the engine speed limit $\lambda_{\max }=0.9, \ldots, 1.15$; for diesel engines $\lambda_{\max }=0.9, \ldots, 1.0$. The calculations are usually made from values $\lambda=0.2$ to $\lambda_{\max }=n_{v \max } / n_{P \max }$ [17]. Where $n_{v \max }$ is the engine speed corresponding to the maximum vehicle speed.

Relations $P=f(n)$ and $T=f(n)$ are described with relations (Eqs. (5), (6)) presented by Bortnicki and Zadorozny [18].

$$
\begin{aligned}
& P=P_{\max }\left(A \lambda+B \lambda^{2}-C \lambda^{3}\right)[\mathrm{kW}], \\
& T=T_{P \max }\left(A+B \lambda-C \lambda^{2}\right)[\mathrm{N} \mathrm{m}] .
\end{aligned}
$$

By making $\mathrm{d} T / \mathrm{d} n=0$ we find:

$$
n_{T \max }=\frac{B \cdot n_{P \max }}{2 \cdot C} .
$$


Substituting the above relation for $n$ to Eq. (6) we obtain:

$$
T_{\max }=T_{P \max }\left(A+\frac{B^{2}}{4 \cdot C}\right) .
$$

Besides, for $n=n_{P \max }$ the equality $P=P_{\max }$ should be fulfilled and then:

$$
A+B-C=1 \quad \Rightarrow \quad C=A+B-1 .
$$

According by Grishkevich [13] coefficients $A, B$ and $C$ may be applicable for gasoline engines and diesel engines and their values are calculated from:

$$
\begin{gathered}
A=\frac{e_{T} e_{n}\left(2-e_{n}\right)-1}{e_{n}\left(2-e_{n}\right)-1}, \quad B=\frac{2 e_{n}\left(1-e_{T}\right)}{e_{n}\left(2-e_{n}\right)^{2}}, \\
C=\frac{e_{n}^{2}\left(1-e_{T}\right)}{e_{n}\left(2-e_{n}\right)-1} .
\end{gathered}
$$

According to Litvinov and Farobin [19] for spark ignition engines, without the engine speed limiter:

$$
A=2-\frac{0.25}{T_{0}}, \quad B=\left(\frac{0.5}{T_{0}}\right)-1, \quad C=\frac{0.25}{T_{0}},
$$

where $T_{0}$ is the coefficient of torque surplus:

$$
T_{0}=\frac{T_{\max }-T_{P \max }}{T_{P \max }}=\left(e_{T}-1\right) .
$$

For diesel engines with engine speed limiter:

$$
\begin{gathered}
A=1-T_{0} \frac{e_{n}\left(2-e_{n}\right)}{\left(e_{n}-1\right)^{2}}, \quad B=2 T_{0} \frac{e_{n}}{\left(e_{n}-1\right)^{2}}, \\
C=T_{0}\left(\frac{e_{n}}{e_{n}-1}\right) .
\end{gathered}
$$

For engines without the engine speed limiter or speed controller a condition $\mathrm{d} P / \mathrm{d} n=0$ for $n=n_{P \max }$ equation should be fulfilled:

$$
A+2 B-3 C=0 .
$$

The method of calculation of the full load engine characteristics (engine speed characteristics) was presented by Bortnicki and Zadorozny [18]. For this purpose, he used the values of the Leiderman coefficients that are in line with the Khlystov proposal (Table 1).

Depending on the engine type (gasoline carbure-

\begin{tabular}{|c|c|c|c|c|}
\hline \multirow[t]{2}{*}{ Coefficients } & \multirow{2}{*}{$\begin{array}{l}\text { Petrol } \\
\text { Carburetor }\end{array}$} & \multicolumn{3}{|l|}{ Diesel } \\
\hline & & $\begin{array}{l}\text { Direct } \\
\text { injection }\end{array}$ & Pre-chamber & $\begin{array}{l}\text { Swirl } \\
\text { chamber }\end{array}$ \\
\hline$A$ & 1.0 & 0.5 & 0.7 & 0.6 \\
\hline B & 1.0 & 1.5 & 1.3 & 1.4 \\
\hline C & 1.0 & 1.0 & 1.0 & 1.0 \\
\hline$n / n_{P \max }$ & \multicolumn{4}{|c|}{$A \lambda+B \lambda^{2}-C \lambda^{3}$} \\
\hline 0.2 & 0.232 & 0.125 & 0.184 & 0.168 \\
\hline 0.3 & 0.363 & 0.258 & 0.300 & 0.279 \\
\hline 0.4 & 0.496 & 0.376 & 0.424 & 0.400 \\
\hline 0.5 & 0.625 & 0.500 & 0.550 & 0.525 \\
\hline 0.6 & 0.744 & 0.624 & 0.672 & 0.646 \\
\hline 0.7 & 0.847 & 0.742 & 0.784 & 0.763 \\
\hline 0.8 & 0.928 & 0.818 & 0.880 & 0.864 \\
\hline 0.9 & 0.981 & 0.936 & 0.954 & 0.945 \\
\hline 1.0 & 1.000 & 1.000 & 1.000 & 1.000 \\
\hline 1.1 & 0.980 & - & - & - \\
\hline
\end{tabular}
tor, direct injected diesel, with a pre-chamber or swirl chamber), we can determine the characteristics having $P_{\max }$ at $n_{P \max }$.

Another solution is the Lenin proposal utilizing one of the relative speed characteristics, showing the relation between $P / P_{\max }$ and $n / n_{P \max }$ [18]. Knowing
Table 1 Leiderman-Khlystov relation coefficient values [18]

the values for carburetor engines and diesel engines (Table 2), we can determine curve $P=f(n)$.

Modern vehicle engines are mostly fuel injected gasoline engines and, turbocharged. In diesel engines, the turbocharged versions are the dominant ones. The literature omits LPG (Liquefied petroleum gas) fueled engines. Only Szpica and Czaban [20] was the attention to this problem drawn and attempts were made to initially estimate the values of the characteristic parameters of the power curve. The results however were based on a small representative group and the publication was only demonstrative.

Partial data for selected engine models are given by Myslowski and Myslowski [21], Prajwowski and Tarczynski [22], Prajwowski and Golebiewski [23].

Hence, the proposal for a more in-depth analysis of the topic along with a comparison against engines that were not directly included in the research.

In the attempts to describe characteristics of a diesel engine fueled with different fuels polynomials are also used, as presented by Stoeck [24], yet the analysis was based on several variants without the statistical analysis on a larger number of samples.

\section{Material and Methods}

\subsection{Subject of the Research}

The investigations were carried out on the full load engine characteristics determined on a chassis dynamometer. The engines were grouped into:

- fuel injected gasoline engines-237 units

- fuel injected, turbocharged gasoline engines-9 units 
Table 2 Lenin relation coefficient values [18]

\begin{tabular}{|c|c|c|c|c|c|c|}
\hline \multirow[t]{3}{*}{ Engine type } & \multicolumn{6}{|c|}{$n / n_{\max }(\%)$} \\
\hline & 20 & 40 & 60 & 80 & 100 & 120 \\
\hline & \multicolumn{6}{|c|}{$P / P_{\max }(\%)$} \\
\hline Petrol-carburetor & 20 & 50 & 73 & 92 & 100 & 92 \\
\hline Diesel-direct injection & 15 & 38 & 62 & 85 & 100 & - \\
\hline Diesel-pre-chamber & 17 & 40 & 65 & 84 & 100 & - \\
\hline
\end{tabular}

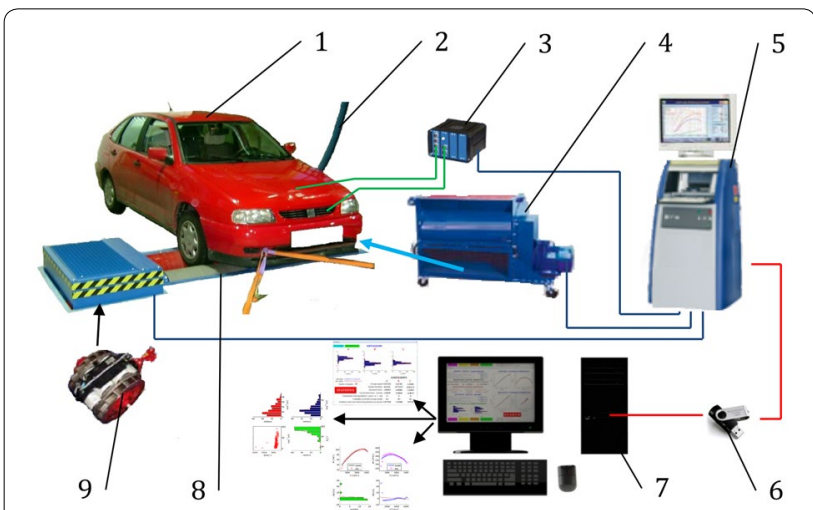

Figure 3 Diagram of the process. 1. Tested vehicle; 2. Exhaust gas extractor; 3. Vehicle signals connector box; 4. Fan; 5. Dynamometer control system; 6 . Portable memory; 7. Computer and software for identification; 8. Twin-roller type chassis dynamometer; 9. Eddy-current brake

- spark ignition LPG, I and II generation engine-64 units

- spark ignition LPG, IV generation-23 units

- naturally aspirated diesel-11 units

- turbocharged diesel-175 units

The authors also had the characteristics of the carburetor engines and they were only used to validate information found in the literature.

\subsection{Research Methodology}

In the investigations, the authors used a chassis dynamometer (LPS 3000 by Maha, Figure 3). Because a large database of results was required, the data collection began in 2004. The vehicles that were the objects of analyses were tested within research projects, classes with students and university promotional events.

On the LPS 3000 dynamometer operating in the loadapplying mode, at a continuous test, the cycle during the measurement is realized assuming a constant acceleration of the roller.

Such a type of chassis dynamometer is a specific solution in the aspect of measurement of power output.
Traditional load-applying chassis dynamometers (while in the measurement mode) by increasing the load by a constant value through the entire cycle 'artificially' increase the system inertia. The LPS 3000 chassis dynamometer adjusts the load on a continuous basis fulfilling conditions.

$$
\varepsilon=\frac{\mathrm{d} \omega}{\mathrm{d} t}=\text { const. }\left[\frac{\mathrm{rad}}{\mathrm{s}^{2}}\right] .
$$

In the preceding investigations, in the beginning of the research cycle preliminary tests were performed. They aimed at checking the reproducibility of the results on one hand (within 3 consecutively repeated tests no errors greater than $1 \%$ of the measurement range were recorded) and determining the full load engine characteristics at different settings of the transmission speeds on the other. It has been observed that only the gear ratio close to 1 allows an assessment of the full measurement range. For overdrives the risk of exceeding the maximum vehicle speed range declared by the manufacturer occurs. The test stand also has a security system against accidental vehicle takeoff from the rollers during the tests. It is rather important because the turbocharged diesel engines have a rapidly increasing torque at maximum charging, which may result in the vehicle uncontrolled takeoff from the stand. The chassis dynamometer systems calculate the slip between the front and the rear axles by monitoring the speeds of the front and rear rollers and can reduce the load in hazardous situations.

The technical data of the test stand have been shown in Table 3. Because the tested vehicles were not property of the university, the tests were not repeated and the conclusions were drawn based on the preliminary tests.

Aside from the chassis dynamometer, the integral part of the measurement track was the software made in Matlab-Simulink, Guide [25].

The $A, B$ and $C$ parameters apply in the entire studied range, hence, their applicability is higher. While searching for the coefficients, a method of non-linear 
Table 3 Basic technical data of the Maha LPS 3000 dynamometer (Maha)

\begin{tabular}{lll}
\hline Parameter & Unit & Values \\
\hline Roller set R100/1 & & \\
Axle load & $\mathrm{t}$ & 2.5 \\
Length & $\mathrm{mm}$ & 3345 \\
Width & $\mathrm{mm}$ & 1100 \\
Height & $\mathrm{mm}$ & 625 \\
Weight & $\mathrm{kg}$ & approx. 1200 \\
Roller length & $\mathrm{mm}$ & 750 \\
Track min. & $\mathrm{mm}$ & 800 \\
Track max. & $\mathrm{mm}$ & 2300 \\
Roller diameter & $\mathrm{mm}$ & 318 \\
Roller axle separation & $\mathrm{mm}$ & 540 \\
Running roller protrusion & $\mathrm{mm}$ & 45 \\
Display range & & \\
Test speed & $\mathrm{kph}$ & max. 250 \\
Wheel power & $\mathrm{kW}$ & max. 260 \\
Traction & $\mathrm{kN}$ & max. 6 \\
Rotation speed & $\mathrm{r} / \mathrm{min}$ & $0-10000$ \\
Measurement accuracy of measure- & $\%$ & \\
ment value & & \\
\hline
\end{tabular}

regression was used, minimizing the $F P E_{1}$ (Final Prediction Error) index by:

$$
F P E_{1}=\frac{m+l}{m(m-1)} \sum_{i=1}^{m}\left(P_{e}-P_{m}\right)^{2}\left[\mathrm{~kW}^{2}\right] .
$$

The minimization was performed numerically through a gradient less method of Nelder-Mead simplex [26]. The minimization was performed with the use of MatlabSimulink, fminsearch procedure [27].

Through a proper selection of coefficients $A, B$ and $C$ we can obtain a high level of experiment to model conformity. The qualitative evaluation of the identification was done through determining of the average and maximum error and the coefficient of determination.

The index $F P E_{2}$ representing the average error has been determined by:

$$
F P E_{2}=\operatorname{MEAN}\left(\frac{\left|P_{e}-P_{m}\right|}{P_{e}}\right) \cdot 100[\%] .
$$

The maximum error value $F P E_{3}$ :

$$
F P E_{3}=\operatorname{MAX}\left(\frac{\left|P_{e}-P_{m}\right|}{P_{e}}\right) \cdot 100[\%] .
$$

And the coefficient of determination adjusted to the degrees of freedom $R^{2}$ :

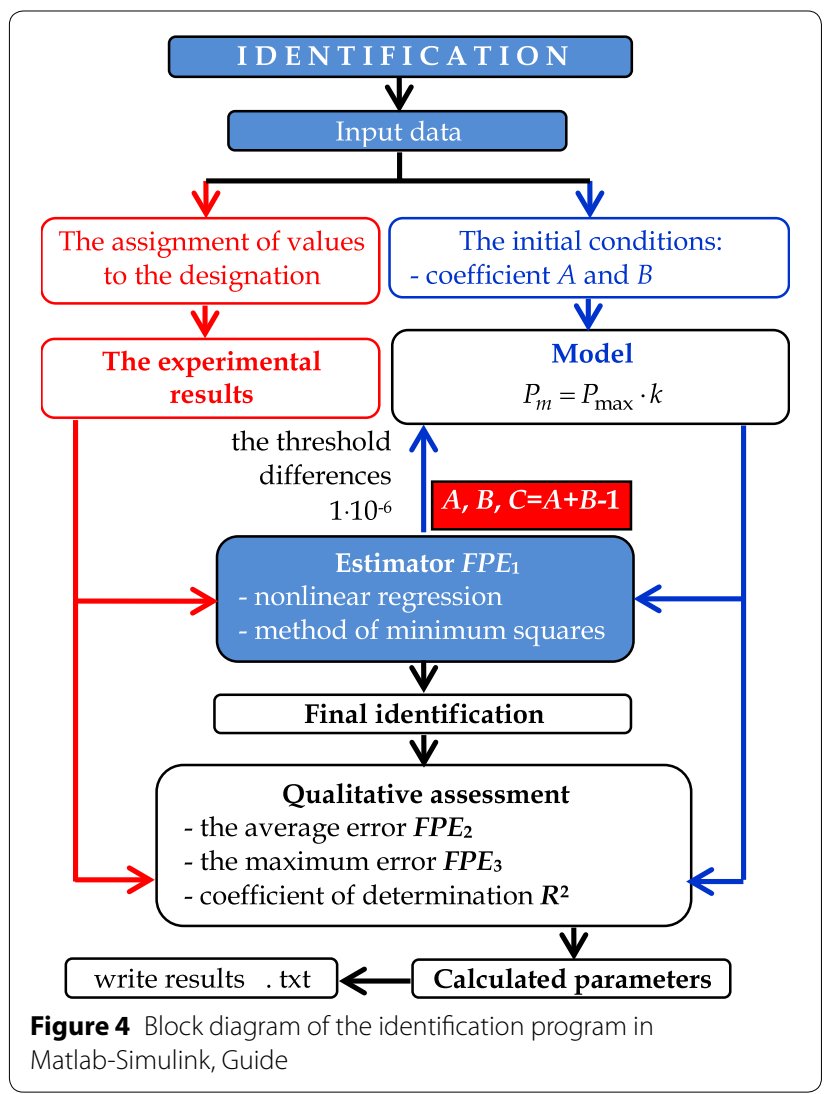

$$
R^{2}=\left(1-\frac{m-l}{m-1} \cdot \frac{\sum_{i=1}^{m}\left(P_{e}-P_{m}\right)^{2}}{\sum_{i=1}^{m}\left(P_{e}-\overline{P_{m}}\right)^{2}}\right) \cdot 100[\%] .
$$

Because the values of the coefficients were identified based on a full range of determined full load engine characteristics, values $A$ and $B$ were sought for and on their basis $C$ was calculated Eq. (9).

To obtain a clear and ordered system of communication in the process of identification, an interface shown in Figure 5 has been developed in Matlab-Simulink, Guide [25]. The block diagram of the program has been shown in Figure 4.

The dialog box of the identification program (Figure 5) contains the function buttons allowing access to selected files, an objective function, relations, procedures and implementations, and the visualization of the results of the identification. The window also shows the identification quality $\left(F P E_{1}, F P E_{2}, F P E_{3}\right.$ and $\left.R^{2}\right)$ and the input parameters. The identification is initiated with the search button. 


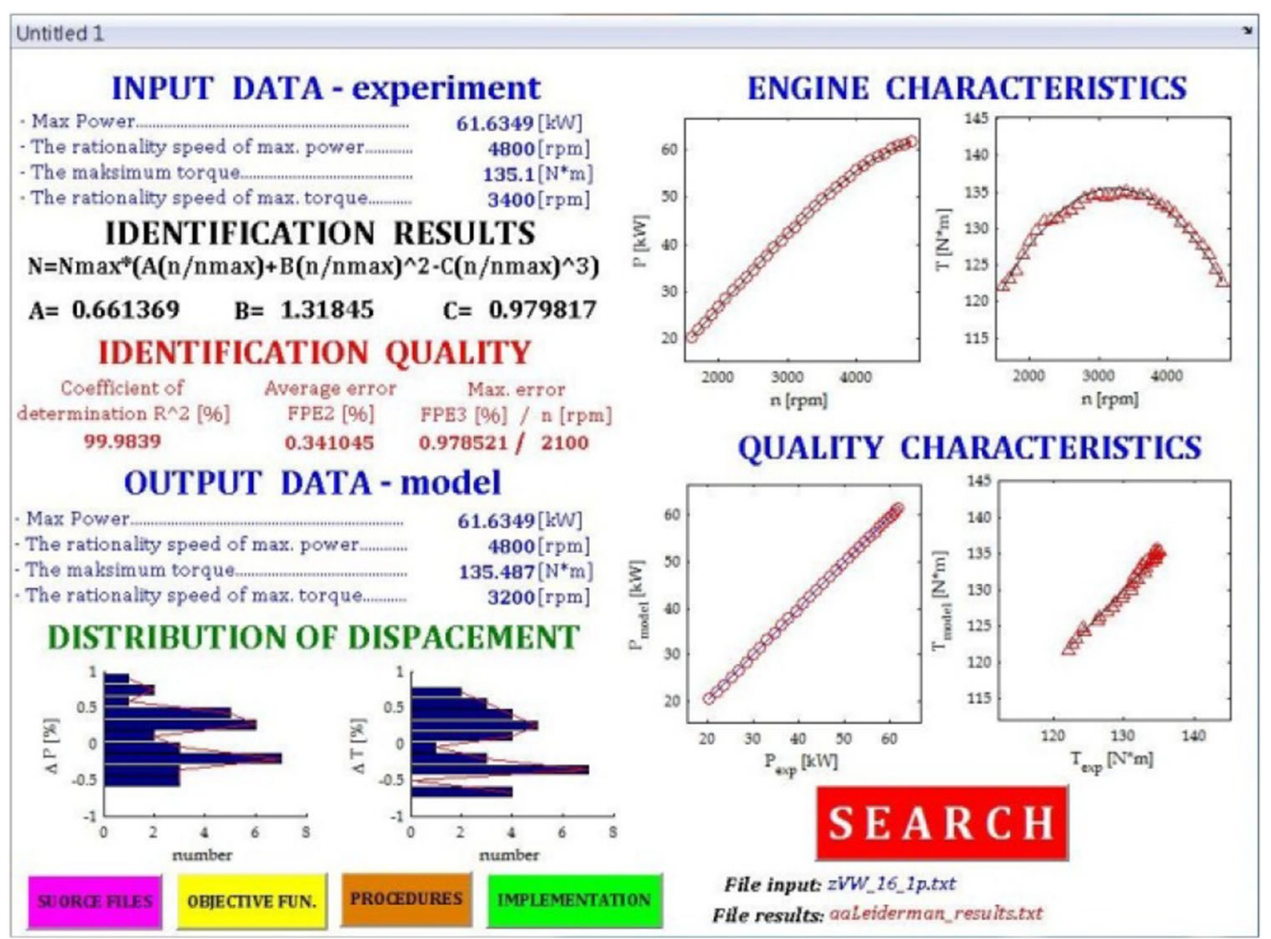

Figure 5 Software panel for the identification of the function parameters created in the Matlab-Simulink, Guide

\section{Results and Discussion}

For the statistical processing of the results MatlabSimulink software and its procedures were used. The results for each of the groups (number of units within a group specified above) were calculated as follows: average, standard deviation, coefficient of asymmetry (skewness), kurtosis, validation of the $t_{\text {test }}$ that allows returning a test decision for the null hypothesis that the data in $x$ come from a normal distribution with the mean equal to the average sample 0 of unknown variance. The alternative hypothesis states that the population distribution does not have a mean equal to average sample. The result $h$ is 1 if the test rejects the null hypothesis at the $5 \%$ significance level and 0 otherwise (Figure 6).

When analyzing the average values (Table 4) we can see the differences in terms of the values presented by Bortnicki [18]. Only naturally aspirated diesel engines approximately correspond to the characteristic values of engines with a pre-chamber, which confirms the correctness of the cited work. Fuel injection and diesel turbocharging significantly modified values $A$ and $B$ and, consequently, $C$. The standard deviation for turbocharged gasoline engines indicates that the results significantly deviate from the average, similarly to turbocharged diesels. It confirms that the Leiderman-Khlystov relation is not correct in these cases.
The value of parameter $A$ in all cases, except LPG IV shows a left-side skewness and $B$-only for turbocharged gasoline and LPG IV.

The value of kurtosis close to 3.0 indicates a normal distribution (Table 5). This condition is fulfilled only by I and II generation LPG and turbocharged diesel engines. Values lower than 3.0 indicate a flattening of the distribution and value greater than 3.0-its slimming. For fuel injected gasoline engines, a significant slimming of the distribution was observed confirming a concentration of the results around the average.

The confidence interval, at which the hypothesis of regularity of the distribution with compliance of averages would not be rejected, remained (for all) below the critical values determined based on the standard deviation and the size the individual samples.

In order to provide the qualitative analysis of the identification, histograms indicating the distribution of errors and the value of the maximum error were developed from each of the measurement (with engine speed indicated).

For gasoline engines (Figure 7) represented by 237 units, it was observed that the average error $F P E_{2}$ concentrates below $2.5 \%$ but it does not exceed $10 \%$. The maximum error $F P E_{3}$ in few cases exceed $100 \%$, which means that one of the points on the model characteristics was significantly deviated from the measurement. As 


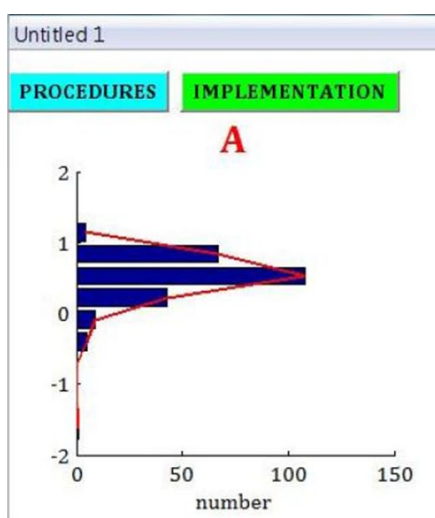

File input: aaleiderman_results_p.txt File results: aaLeiderman_statistics_p.txt

Number of samples 237

\section{STATISTICS}

\section{HISTOGRAMS}

B

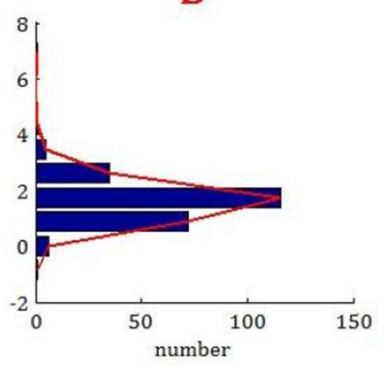

A

Average sample $\mathbf{0 . 5 1 1 1 6 2}$

Standard deviation $\mathbf{0 . 3 1 3 2 1}$

Asymmetry factor $\quad-2.02023$

Concentration factor - kurtosis $\mathbf{1 4 . 8 5 4 9}$

Confirmation of the hypothesis: 0 - good; 1 or -1 - bad 0

Probability at witch the average outside $\quad 0.5$

Confidence interval at which the hypothesis is not rejected $\mathbf{0 . 4 7 7 5 6 5}$

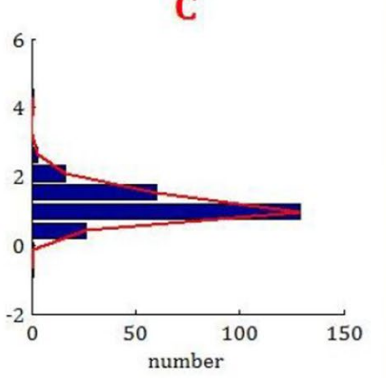

COEFFICIENTS

$\begin{array}{cc}\text { B } & C \\ 1.61785 & 1.12902 \\ 0.775373 & 0.501174 \\ 1.89906 & 1.31893 \\ 15.8036 & 12.8675 \\ 0 & 0 \\ 0.5 & 0.5 \\ 1.53468 & 1.07526\end{array}$

Figure 6 Software panel for statistical calculations in the Matlab-Simulink, Guide

Table 4 Identification results: average samples, standard deviation, asymmetry factor

\begin{tabular}{|c|c|c|c|c|c|c|c|}
\hline \multirow[t]{2}{*}{ Supply system } & \multirow{2}{*}{$\begin{array}{l}\text { Number } \\
\text { of samples }\end{array}$} & \multicolumn{2}{|c|}{ Average samples } & \multicolumn{2}{|c|}{ Standard deviation } & \multicolumn{2}{|c|}{ Asymmetry factor } \\
\hline & & $A$ & $B$ & $A$ & $B$ & $\bar{A}$ & $B$ \\
\hline Fuel inj. gasoline & 237 & 0.511162 & 1.617855 & 0.313210 & 0.775373 & -2.020228 & 1.899060 \\
\hline Fuel inj. turbocharged gasoline & 9 & 0.295132 & 2.120719 & 0.316841 & 0.818221 & -0.413566 & -0.108163 \\
\hline Spark ignition LPG, I and II gen. & 64 & 0.570199 & 1.574281 & 0.279793 & 0.693003 & -0.279568 & 0.017163 \\
\hline Spark ignition LPG, IV gen. & 23 & 0.542335 & 1.544406 & 0.294183 & 0.652313 & 0.856567 & -0.625658 \\
\hline Naturally aspirated diesel & 11 & 0.738505 & 1.194464 & 0.364956 & 0.840597 & -1.105769 & 1.956045 \\
\hline Turbocharged diesel & 175 & 0.261225 & 2.568185 & 0.574244 & 1.348992 & -0.452776 & 0.529523 \\
\hline
\end{tabular}

Table 5 Identification results: kurtosis, confidence interval

\begin{tabular}{|c|c|c|c|c|c|}
\hline \multirow[t]{2}{*}{ Supply system } & \multirow[t]{2}{*}{ Number of samples } & \multicolumn{2}{|l|}{ Kurtosis } & \multicolumn{2}{|c|}{ Confidence interval } \\
\hline & & $A$ & B & $A$ & $B$ \\
\hline Fuel inj. gasoline & 237 & 14.854857 & 15.803642 & 0.477565 & 1.534683 \\
\hline Fuel inj. turbocharged gasoline & 9 & 1.655907 & 2.266098 & 0.098739 & 1.613545 \\
\hline Spark ignition LPG, I and II gen. & 64 & 2.927065 & 3.067192 & 0.511813 & 1.429668 \\
\hline Spark ignition LPG, IV gen. & 23 & 5.101773 & 5.116707 & 0.437003 & 1.310846 \\
\hline Naturally aspirated diesel & 11 & 4.916271 & 6.344486 & 0.539064 & 0.735096 \\
\hline Turbocharged diesel & 175 & 2.737545 & 2.849502 & 0.189442 & 2.399555 \\
\hline
\end{tabular}



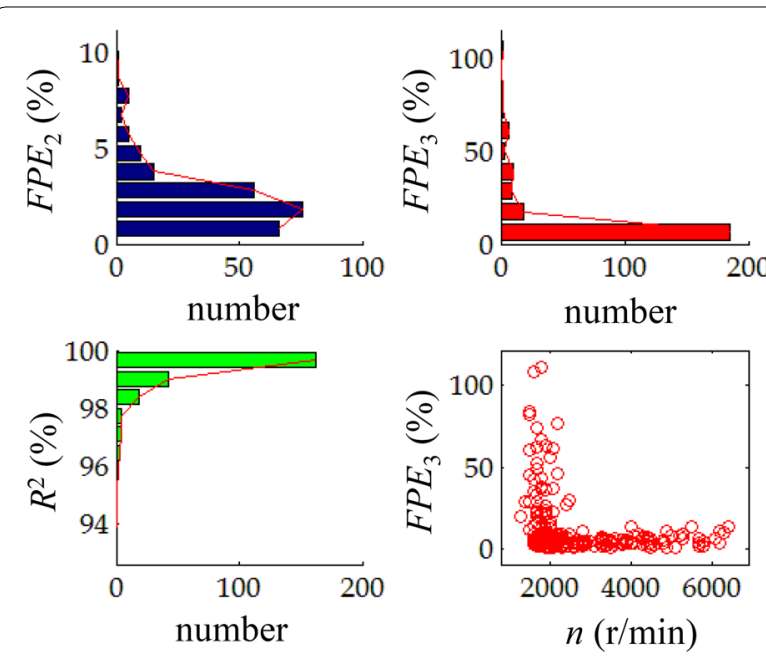

Figure 7 Average, maximum error end determination coefficient for identification—fuel injected gasoline

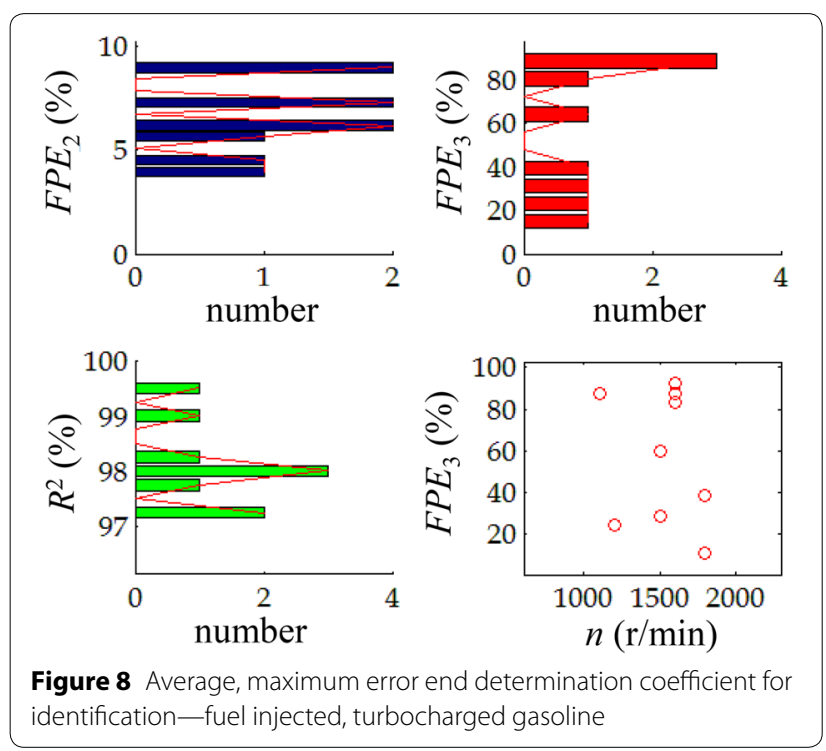

we can see, significant deviations were observed for low engine speeds, where the dynamometer adapts the load to the current conditions, which, again, requires quick response from the engine controller. Further, the maximum error stabilizes around $10 \%$.

Gasoline fuel injected and turbocharged engines (Figure 8) were represented only by 9 units and that is why the statistical evaluation was difficult. It was observed that maximum error $F P E_{3}$ reaches peak values at low engine speeds.

Alternative fuel spark ignition engines (LPG of I and II generation, Figure 9) represented by 64 units gave an average error $\left(F P E_{2}\right)$ around $2 \%$ and maximum error

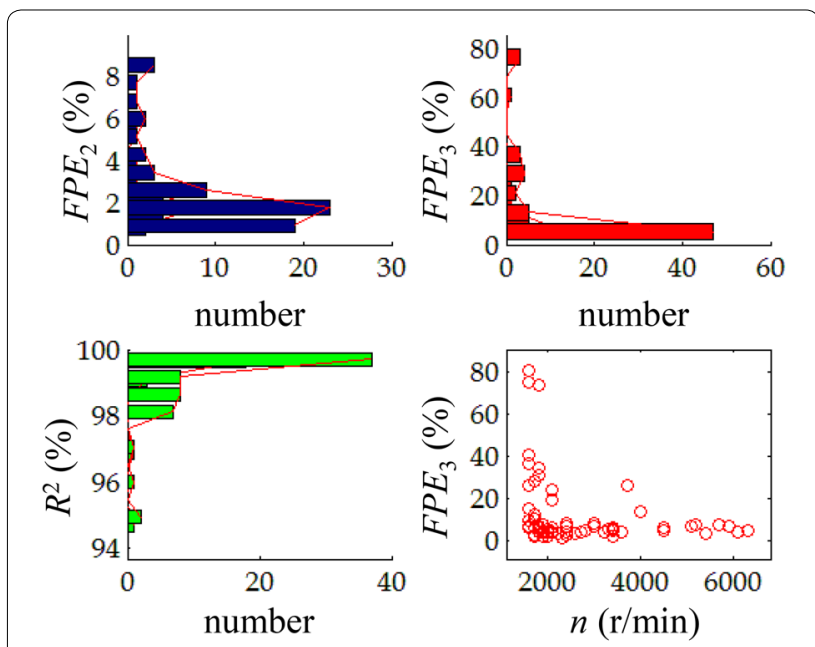

Figure 9 Average, maximum error end determination coefficient for identification—spark ignition LPG, I and II generation

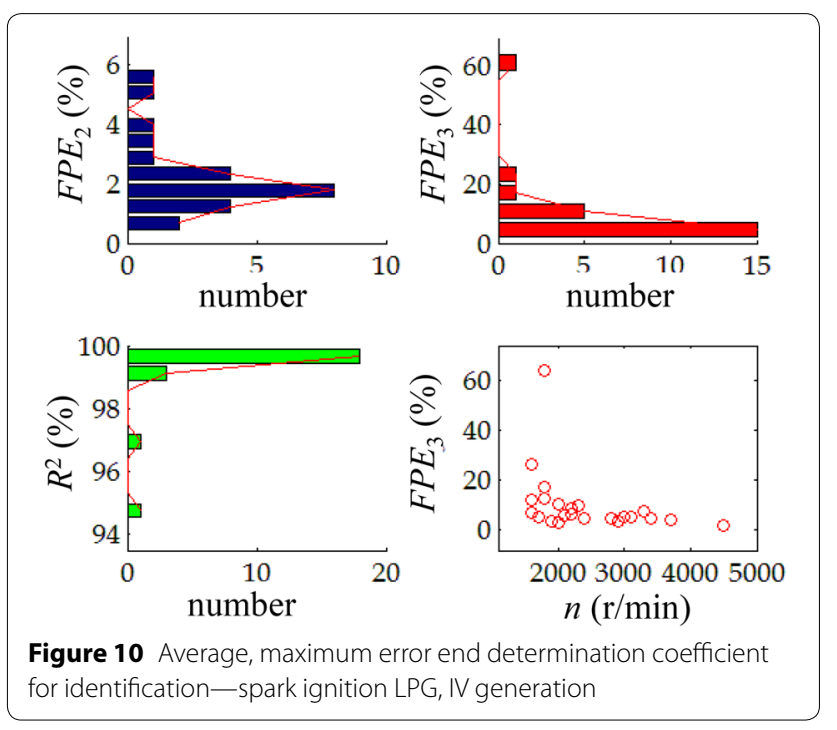

$\left(F P E_{3}\right)$ of $10 \%$. Similarly to the previous case, we can see a significant deviation of the model from the experiment at low engine speeds. Similarly, the engines powered by IV generation LPG (Figure 10) represented by 23 units: average error $\left(F P E_{2}\right)$ around $2 \%$ and maximum error $\left(F P E_{3}\right)$ of $10 \%$. A deviation at low engine speed was also observed.

Naturally aspirated diesel engines (Figure 11) in the amount of 11 units have shown the lowest error values for average $F P E_{2}$ approx. $1 \%$ and the maximum $F P E_{3}$ approx. $2 \%$. The maximum error does not occur for low engine speeds as in the previous cases.

For turbocharged diesel engines (Figure 12), represented by 175 units it was observed that average $F P E_{2}$ oscillated below $5 \%$ but does not exceed $15 \%$. Maximum 


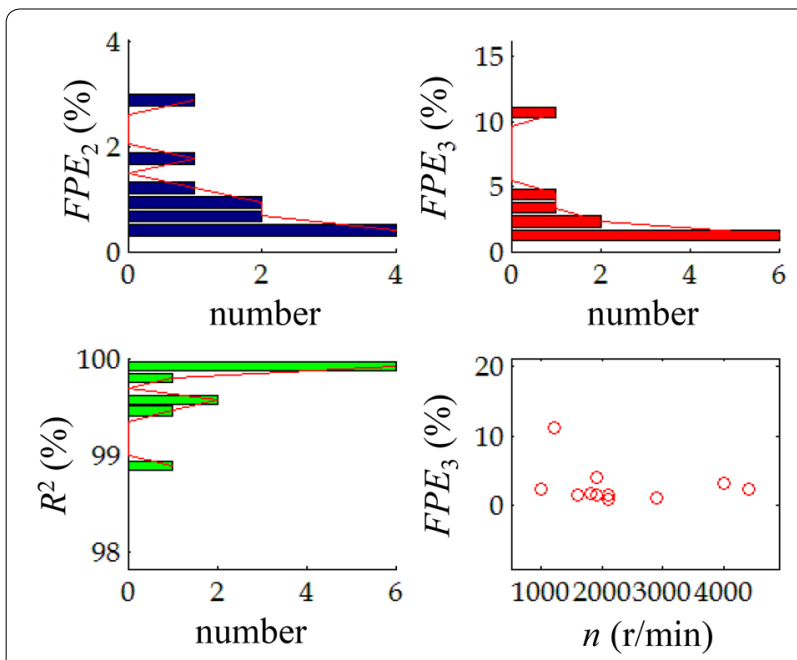

Figure 11 Average, maximum error end determination coefficient for identification — naturally aspirated diesel
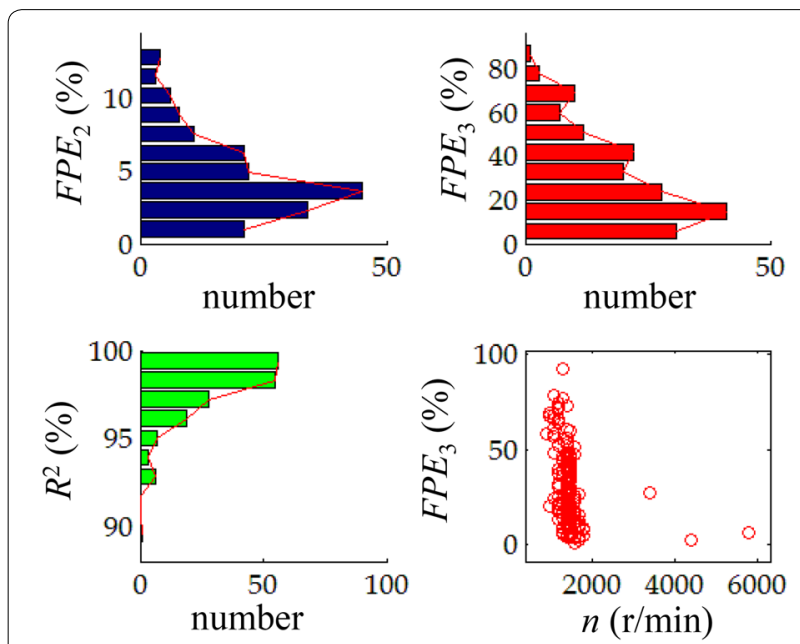

Figure 12 Average, maximum error end determination coefficient for identification - turbocharged diesel

$\mathrm{FPE}_{3}$ in few cases exceeds $80 \%$ but oscillated around $17 \%$. In this case, the problem of the onset of the measurement becomes prominent, as there is the additional reaction of the turbocharger. Only in 3 cases was the occurrence of the maximum errors observed outside of the range of low engine speeds.

In the further stages, the authors presented the courses of the reference characteristics calculated based on the determined coefficients and Eq. (5) against all recorded measurements in the analyzed groups.

The comparison of fuel injected gasoline engines with the reference characteristics indicates that the average values oscillate around 0 deviation (Figure 13). The
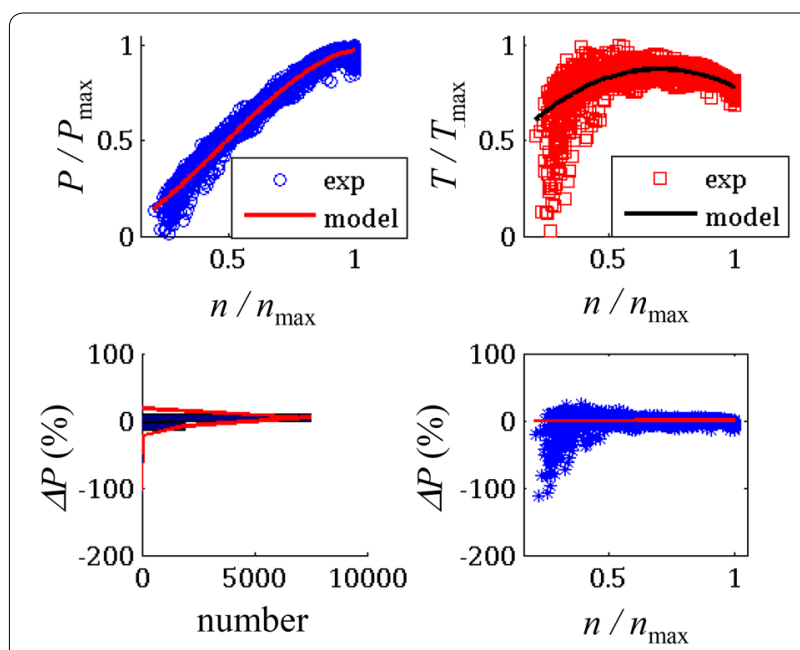

Figure 13 Results of the measurements and the reference characteristics - fuel injected gasoline

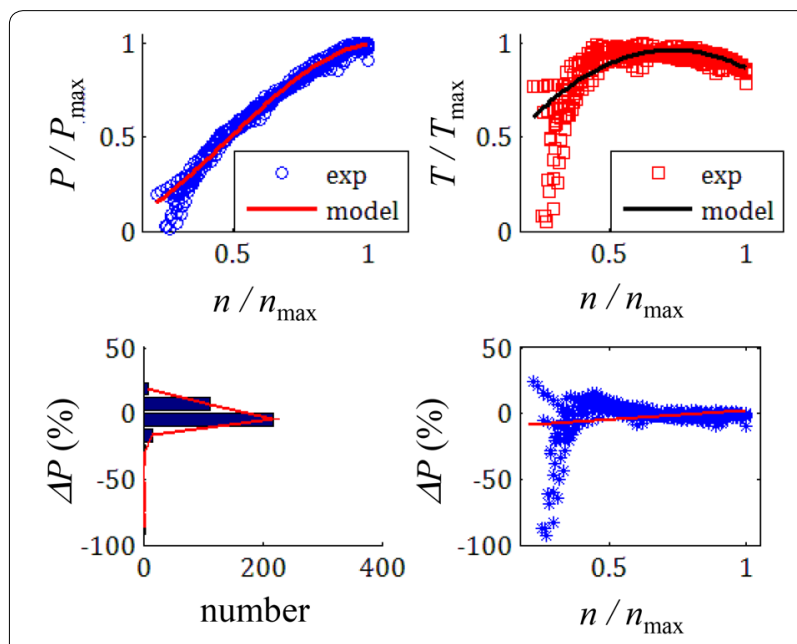

Figure 14 Results of the measurements and the reference characteristics-fuel injected, turbocharged gasoline

greatest discrepancies occur at the beginning of the characteristics. The resultant torque also indicates the averaging of the results of identification.

Gasoline turbocharged engines, similarly to the naturally aspirated ones in their results oscillate around 0 deviation (Figure 14), however greater discrepancy occurs at low engine speeds, which makes the value go down below 0 at this point.

Alternative fuel engines (I and II generation LPG) may be compared to carburetor type fuelling (single central fuel source). That is why the functional description of this characteristics seems correct in this case. (The trend of deviation around 0 with the discrepancy 

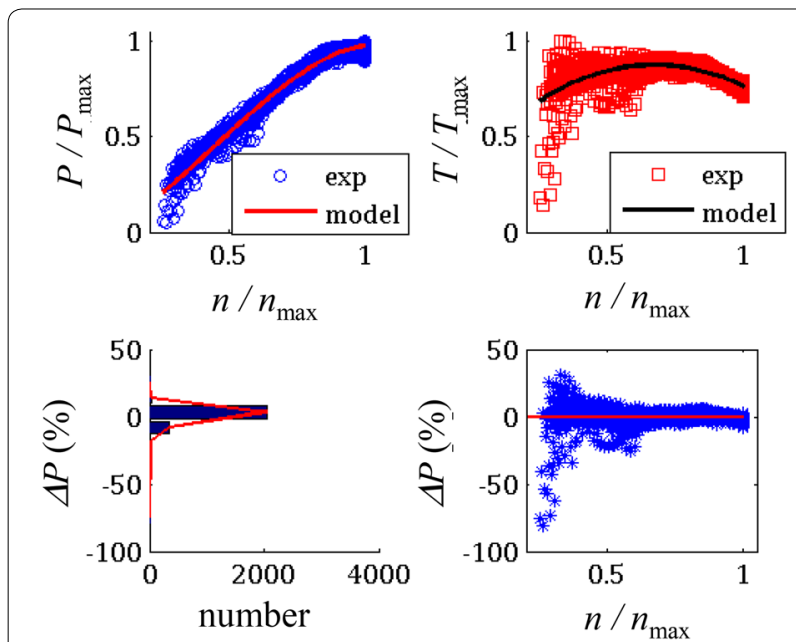

Figure 15 Results of the measurements and the reference characteristics - spark ignition LPG, I and II generation
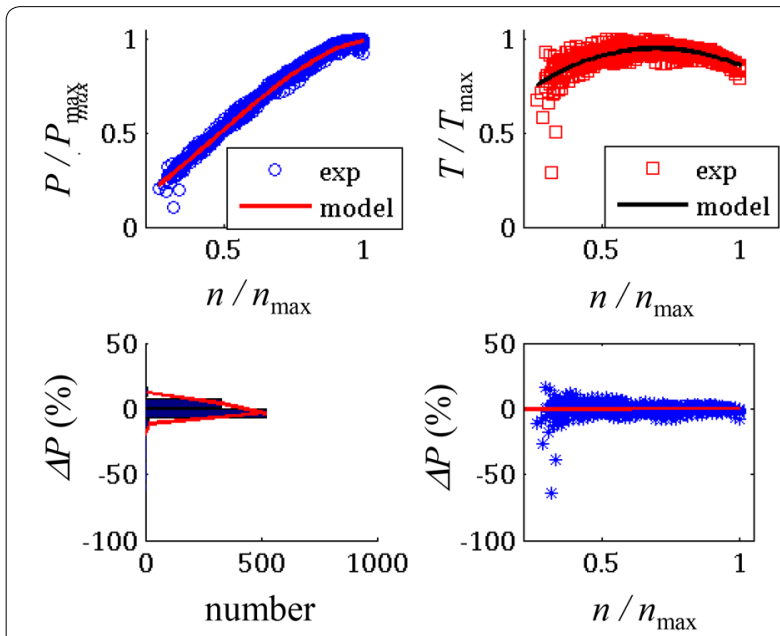

Figure 16 Results of the measurements and the reference characteristics — spark ignition LPG, IV generation

at low engine speeds has been confirmed, shown in Figure 15).

LPG IV fueled engines compared to the above-presented ones have the best results (Figure 16). Both the power and the resultant torque show the least discrepancies out of all spark ignition engines.

Diesel engines were the basis for the Leiderman, Khlystov and Lenin studies. We can see the aptness of the declarations on the functional correctness of the mathematical description (Figure 17). The discrepancies merely exceeded $10 \%, 0$ on average.

For turbocharged diesel engines we can see that the model curve equally oscillates around 0 deviation. The
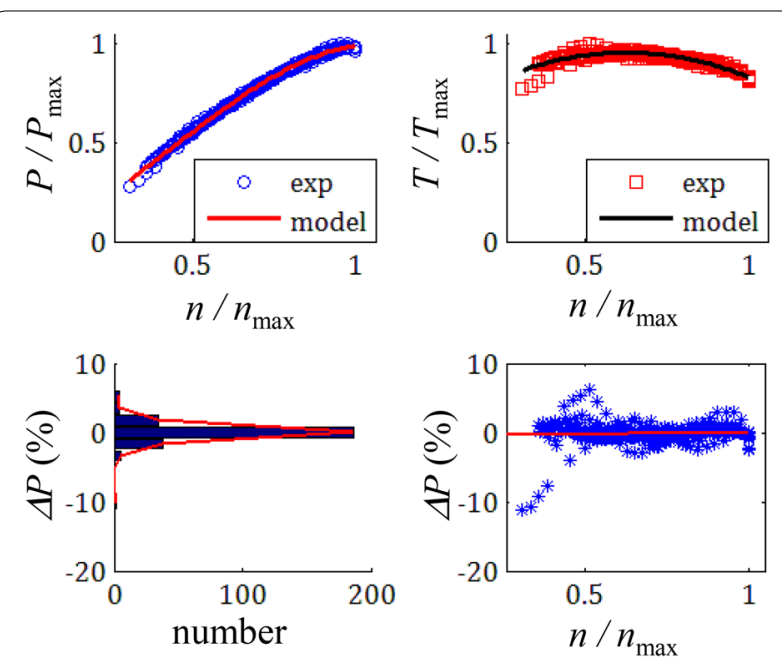

Figure 17 Results of the measurements and the reference characteristics — naturally aspirated diesel

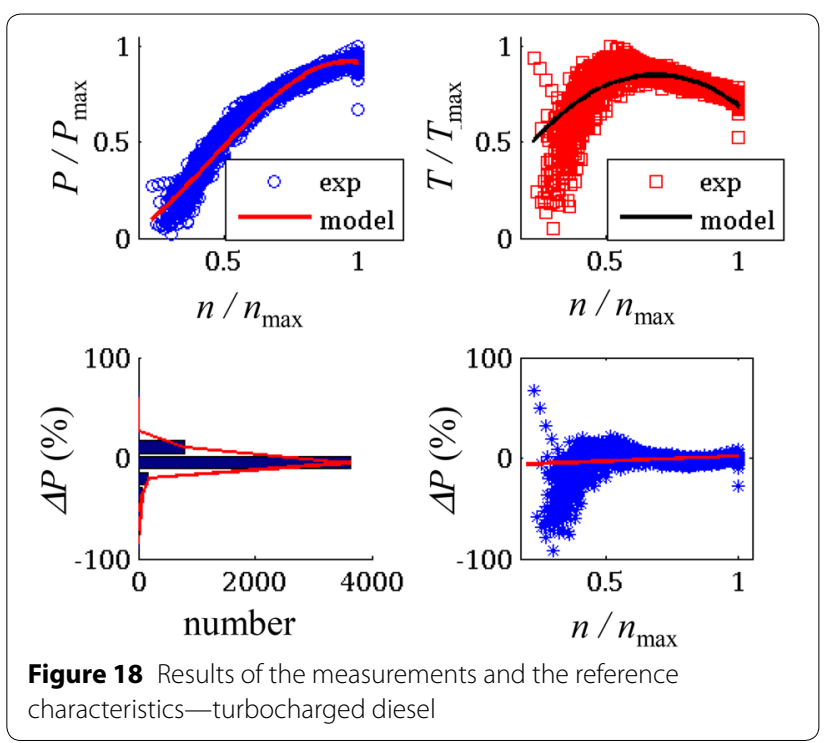

discrepancy trend goes down below 0 for low engine speeds (Figure 18).

The comparison of all with the model lines marked indicated the necessity of modification of the functional description for both diesel and gasoline turbocharged engines. Supercharging aims at increasing the torque at low engine speeds, thus making the function more convex. Later, the authors are planning to introduce their own function for the description of this type of engines.

\section{Assessment of Application}

For the assessment of the applicability of the determined coefficients, example characteristics were used of engines out of the research group. The analysis was limited to one 
Table 6 Model to experiment comparison of the maximum power and torque

\begin{tabular}{|c|c|c|c|c|c|c|c|c|c|c|c|c|}
\hline \multirow[t]{2}{*}{ Engine } & \multicolumn{2}{|c|}{ BMW 1.8MPi } & \multicolumn{2}{|l|}{ Audi $1.8 \mathrm{~T}$} & \multicolumn{2}{|c|}{ Audi 1.8 LPG I } & \multicolumn{2}{|c|}{ Seat 1.8 LPG IV } & \multicolumn{2}{|c|}{ Renault 1.8D } & \multicolumn{2}{|c|}{ Toyota 2.0TD } \\
\hline & $\begin{array}{l}P(\mathrm{~kW}) \\
n(\mathrm{r} / \mathrm{min})\end{array}$ & $\begin{array}{l}T(\mathrm{Nm}) \\
n(\mathrm{r} / \mathrm{min})\end{array}$ & $\begin{array}{l}P(\mathrm{~kW}) \\
n(\mathrm{r} / \mathrm{min})\end{array}$ & $\begin{array}{l}T(\mathrm{Nm}) \\
n(\mathrm{r} / \mathrm{min})\end{array}$ & $\begin{array}{l}P(\mathrm{~kW}) \\
n(\mathrm{r} / \mathrm{min})\end{array}$ & $\begin{array}{l}T(\mathrm{Nm}) \\
n(\mathrm{r} / \mathrm{min})\end{array}$ & $\begin{array}{l}P(\mathrm{~kW}) \\
n(\mathrm{r} / \mathrm{min})\end{array}$ & $\begin{array}{l}T(\mathrm{Nm}) \\
n(\mathrm{r} / \mathrm{min})\end{array}$ & $\begin{array}{l}P(\mathrm{~kW}) \\
n(\mathrm{r} / \mathrm{min})\end{array}$ & $\begin{array}{l}T(\mathrm{Nm}) \\
n(\mathrm{r} / \mathrm{min})\end{array}$ & $\begin{array}{l}P(\mathrm{~kW}) \\
n(\mathrm{r} / \mathrm{min})\end{array}$ & $\begin{array}{l}T(\mathrm{Nm}) \\
n(\mathrm{r} / \mathrm{min})\end{array}$ \\
\hline \multirow[t]{2}{*}{ Exp. } & 84.58 & 154.30 & 125.11 & 281.60 & 60.09 & 146.10 & 63.03 & 121.60 & 63.98 & 175.80 & 102.75 & 331.20 \\
\hline & 5900 & 4200 & 5300 & 3400 & 4400 & 3300 & 5500 & 4100 & 4100 & 2200 & 3600 & 2300 \\
\hline \multirow[t]{2}{*}{ Mod. } & 85.44 & 149.33 & 126.08 & 245.54 & 60.09 & 144.97 & 63.03 & 119.41 & 64.43 & 167.05 & 102.78 & 316.85 \\
\hline & 6100 & 4200 & 5500 & 4000 & 4400 & 3000 & 5500 & 3900 & 4200 & 2600 & 3500 & 2500 \\
\hline
\end{tabular}
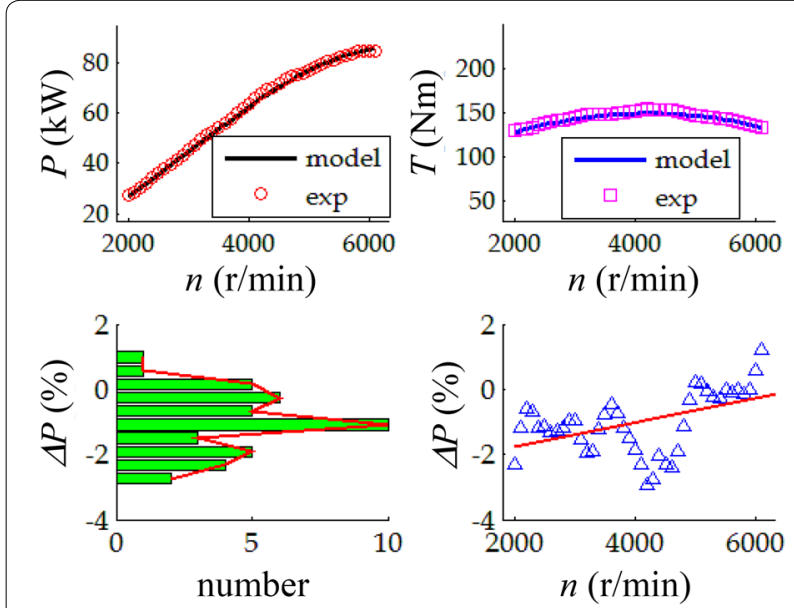

Figure 19 Full load engine characteristics of BMW 1.8 MPi

engine for each group and the results were presented in Table 6.

By putting values from Table 4 to Eq. (5) for gasoline engines and comparing them with the BMW 1.8 MPi engine we can see the values are convergent (Figure 19). The differences in power are within the $\pm 2 \%$, range deviating $1 \%$ on average. Model approximation gives a difference in the maximum torque of approx. $5 \mathrm{Nm}$ at the same engine speed.

The turbocharged gasoline engine significantly deviates for the model values, which indicates inadequacy of the adopted function variant (Figure 20). Both the torque and the power differ in their peak values and the corresponding engine speeds. The differences in the power are maximum $18 \%$.

I and II generation LPG in this comparison represents a central fuel dosage system. The peak power values are convergent (Figure 21). The torque is different by just above $1 \mathrm{~N} \mathrm{~m}$ and the corresponding speed-300 r/min. The difference does not exceed $5 \%$.

The situation is similar for the Seat 1.8 LPGIV engine (Figure 22). The difference does not exceed 5\%.

Also, the Renault 1.9D engine can be correctly adapted using the determined coefficients. The
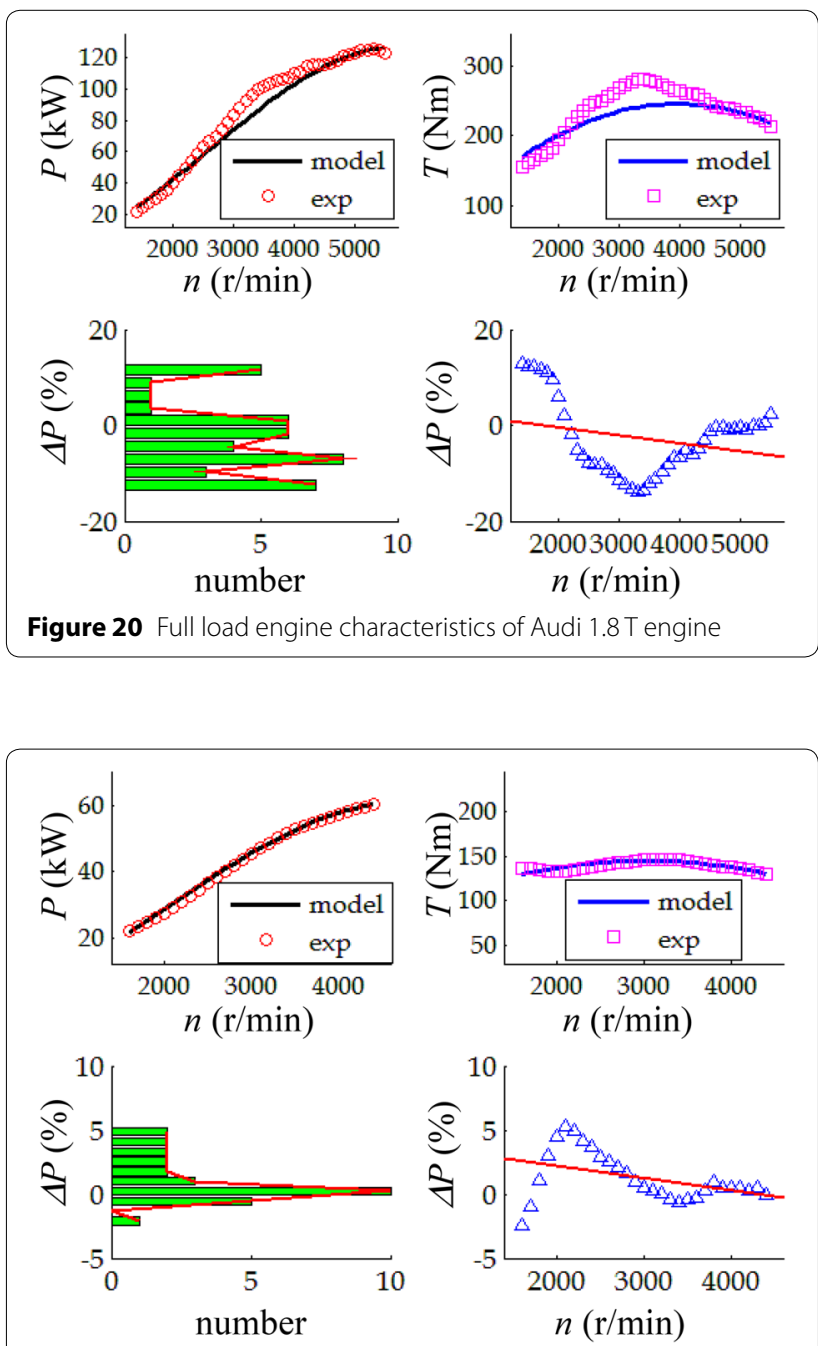

Figure 21 Full load engine characteristics of Audi 1.8 LPG I

difference does not exceed 4\% (Figure 23). In this case, the maximum values of power and torque and the corresponding engine speeds show the smallest discrepancies out of the compared engines.

Retrofitting of a turbocharger in a vehicle (Toyota 2.0TD) shows the problem of function inadequacy at 

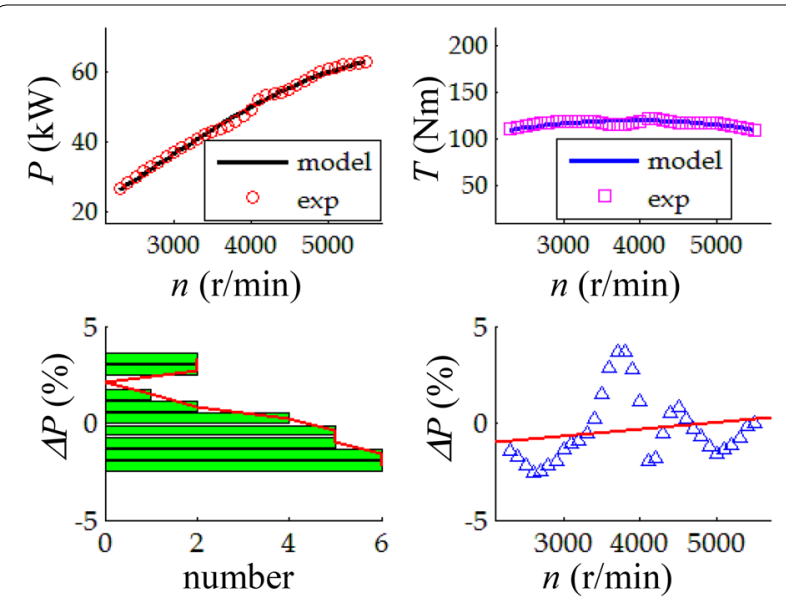

Figure 22 Full load engine characteristics of Seat 1.8 LPG IV
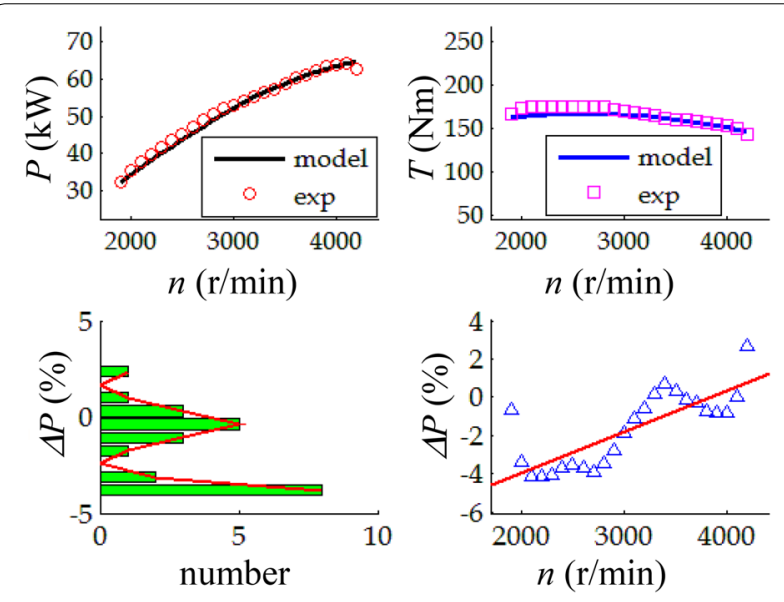

Figure 23 Full load engine characteristics of Renault 1.9D

abrupt increment of torque at low engine speeds (Figure 24). At this point, the differences may reach up to $50 \%$. Later, however, it stabilizes around 5\%.

Because the authors had several recorded characteristics of carburetor engines (obsolete today) they decided to verify the correctness of the assumption of 1 by values $A, B$ and $C$. Based on the example of the VW 1.3 engine we can see (Figure 25a) that the values were determined correctly but the boundary difference is $15 \%$.

Having appropriate software for the identification, $A=0.831731, B=1.205236$ and $C=1.036967$ were determined. The maximum difference of $6 \%$ was obtained in this way (Figure 25b).
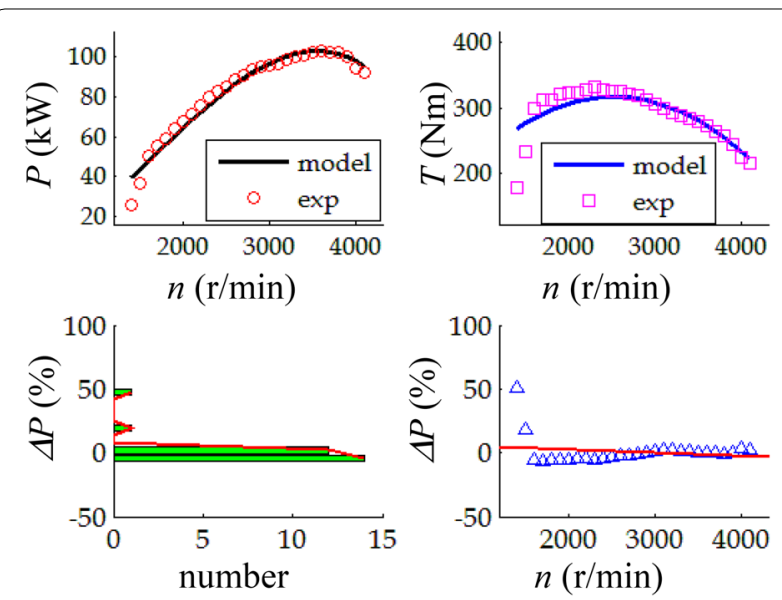

Figure 24 Full load engine characteristics of Toyota 2.0TD engine

\section{Conclusions}

(1) A method of calculation of full load engine characteristics has been presented in the paper based on hyperbolic equation where, at a correct selection, we can obtain compliance of the model with the experiment (these differences do not exceed $5 \%$ in most of the treated cases).

(2) The values of the characteristic coefficients of the power equation have been determined for engines that have not yet been analyzed in the literature (LPG).

(3) The correctness of the values presented for older variants of fuel systems has been confirmed.

(4) An applicability of the determined values was confirmed by the comparison with example engines, which were not part of the main research.

(5) The number of the tested vehicles with gasoline fuel injected and turbocharged engines and naturally aspirated diesel was insufficient for the statistical evaluation.

(6) The recently very popular turbocharging, particularly in spark ignition engines, forces the application of other functions (such a polynomials) for the description of the engine characteristics.

(7) It should be noted that the number of the tested vehicles was rather low compared to the number of available makes, models of the distinguished vehicle groups. That is why, some of the results were supported with vehicle names, which should not constitute a basis for the evaluation of the entire model group of a given make.

It is noteworthy that the test objects were random products of a given brand and model, which is why the 

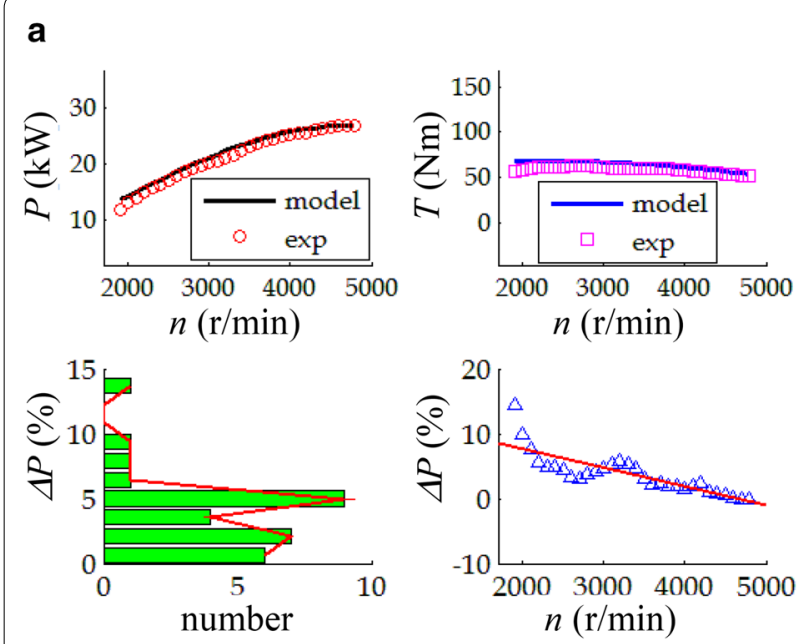

Figure 25 Full load engine characteristics of VW 1.3
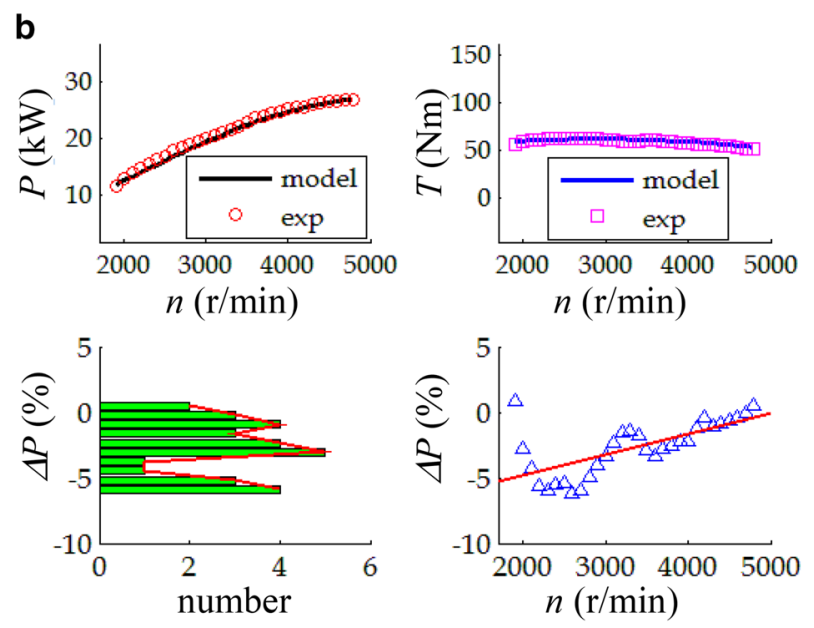

results were supplemented by the manufacturers names. This however cannot be a basis for the assessment of the entire model group of a given make.

\section{Abbreviations}

$n$ : Engine speed (rad/s) or ( $r / m i n) ; T$ : Maximum value of torque (Nm); P: Power $(\mathrm{kW}) ; m$ : Number of points of the identified curve; $I$ : Number of significant model coefficients; $A, B, C$ : Coefficients of the curve; max: Maximum; $P_{\max }$ : Corresponding to the maximum power; $T_{\text {max }}$ : Corresponding maximum torque; $e$ : Experimental; m: Model; -: Average; FPE: Final prediction error; LPG: Liquefied petroleum gas; V.A.G.: Volkswagen Audi Group.

\section{Authors' Contributions}

DS was in charge of the whole manuscript. The author read and approved the final manuscript.

\section{Authors' Information}

Dariusz Szpica, born in 1971, is currently a PhD MEng at Faculty of Mechanical Engineering, Bialystok University of Technology, Poland. His research interests include fuel supply in combustion engines.

\section{Competing Interests}

The author declares no competing interests.

\section{Funding}

The research has been carried out within work no. S/WM/1/2018 realized at Bialystok University of Technology and financed from the funding allocated for science by the Ministry of Science and Higher Education-Poland.

Received: 26 March 2019 Revised: 21 September 2019 Accepted: 19 November 2019

Published online: 29 November 2019

\section{References}

[1] D Szpica, J Piwnik, M Sidorowicz. The motion storage characteristics as the indicator of stability of internal combustion engine - receiver cooperation. Mechanika, 2014, 20(1): 108-112.

[2] H S Jo, Y I Park, J M Lee, et al. A study on the improvement of the shift characteristics for the passenger car automatic transmission. International Journal of Vehicle Design, 2000, 23(3-4): 307-328.
[3] M R Gabdullin, N M Filkin, R S Muzafarov, et al. Development of a KESU with an automatic stepless transmission of a very small passenger car (ATV). Izhevsk: Izhevski State Technological University, 2012: 129-136. (in Russian)

[4] M Koic, D Obradovic, Z Bogdanovic. Dynamic analysis of vehicle propulsion group with nonlinear characteristics of supports and arbitrary motion of the car body. International Journal of Vehicle Design, 2001, 26 (5): 523-540

[5] U K Lee, C S Han. A method for predicting dynamic behaviour characteristics of a vehicle using the screw theory - part I. Proceedings of the Institution of Mechanical Engineers, Part D: Journal of Automobile Engineering, 2008, 222 (D1): 65-77.

[6] L Li, C Sandu. On the impact of cargo weight, vehicle parameters, and terrain characteristics on the prediction of traction for off-road vehicles. Journal of Terramechanics, 2007, 44 (3): 221-238.

[7] S Moridpour, G Rose, M Sarvi, et al. Influence of the surrounding traffic characteristics on lane changing decision of heavy vehicle drivers. Road \& Transport Research, 2012, 21(3): 19-33.

[8] R Pueboobpaphan, B van Arem. Driver and vehicle characteristics and platoon and traffic flow stability. Understanding the relationship for design and assessment of cooperative adaptive cruise control transport. Transportation Research Record, 2010, 2189: 89-97.

[9] G An, Z Y Wang, C Q Zhang, et al. The torque measurement and analysis of state characteristic on power transmission system of vehicle. Proceedings of the 6th International Symposium on Test and Measurement (ISTM) (ed TD Wen), Dalian, China, 1-4 June 2005, 1-9: 4556-4560.

[10] A Stonys, J Sapragonas, S Mockus. The analogy method for the description of external characteristic of inner combustion engines. Transport, 2004, 5(XIX): 214-218.

[11] T Rothengatter, R De Bruin. The influence of drivers attitudes and vehicle characteristics on speed choice on highways and safety consequences. International Journal of Vehicle Design, 1998, 9(4-5): 579-585.

[12] F Rawski, D Szpica. Simulation methods applied in the investigations of inlet system of piston combustion engines. Przeglad Mechaniczny, 2005, 2: 14-19. (in Polish)

[13] A I Grishkevich. Cars theory. Minsk: Higer School, 1986. (in Russian)

[14] J Mysłowski, J Koltun. Flexibility of piston combustion engines. Warsaw: WNT, 2000. (in Polish)

[15] D Szpica, J Czaban. The flexibility of car the diesel engines on example of group 1,9TDi of firm the Volkswagen. Combustion Engines, 2011, 3 (50): 1-6. (in Polish)

[16] D Szpica. Coefficient of engine flexibility as a basis for the assessment of vehicle tractive performance. Chinese Journal of Mechanical Engineering, 2019, 32:39. https://doi.org/10.1186/s10033-019-0352-8. 
[17] W A Chernyshev. Traction-dynamic and fuel-economic calculation of the automobile: Methodical recommendations for the execution of the course work. Moscow: Russian State Agrarian University, 2002. (in Russian)

[18] P I Bortnicki, W I Zadorozny. Traction-speed characteristics of cars. Minsk: Higher school, 1978. (in Russian)

[19] A S Litvinov, J E Farobin. Car: Operational properties theory. Moscow: Mashinostroienie, 1989. (in Russian)

[20] D Szpica, J Czaban. Leideman's equation and modern construction of internal combustion engine. Przeglad Mechaniczny, 2010, 6: 24-29. (in Polish)

[21] J Myslowski, J Myslowski. Leidemann's formulas coefficients correction for presents requirements of technology state. Combustion Engines, 2007, SC2: 418-423.

[22] K Prajwowski, G Tarczynski. Analytical determination of partial power characteristics using Leidemann's formulas. The Archives of Automotive Engineering, 2005, 1: 49-57. (in Polish)
[23] K Prajwowski, W Golebiewski. Analytical determination of the characteristics of engine power Fiat 1.3 JTD. Journal of KONES Powertrain and Transport, 2014, 21(2): 267-272.

[24] T Stoeck. Mathematical description of the external characteristics of compression-ignition engine fuelled with different types of fuel. The Archives of Automotive Engineering, 2010, 2: 111-118. (in Polish)

[25] ST Smith. Matlab Advanced GUI Development. Indianapolis: Dog Ear Publishing, 2006.

[26] J C Lagarias, J A Reeds, M H Wright, et al. Convergence properties of the Nelder-Mead simplex method in low dimensions. SIAM Journal on Optimization, 1998, 9(1): 112-147.

[27] WY Yang, W Cao, T S Chung, et al. Applied numerical methods using MATLAB. Hoboken, New Jersey: John Wiley \& Sons Inc., 2005.

\section{Submit your manuscript to a SpringerOpen ${ }^{\circ}$ journal and benefit from:}

- Convenient online submission

- Rigorous peer review

- Open access: articles freely available online

- High visibility within the field

- Retaining the copyright to your article

Submit your next manuscript at $\boldsymbol{\nabla}$ springeropen.com 